\title{
Beyond microbes: are fauna the next frontier in soil biogeochemical models?
}
A. Stuart Grandy* ${ }^{1}$
William R. Wieder ${ }^{2,3}$
Kyle Wickings ${ }^{4}$
Emily Kyker-Snowman ${ }^{1}$

${ }^{1}$ Department of Natural Resources and the Environment, University of New Hampshire, Durham, New Hampshire 03824

${ }^{2}$ Climate and Global Dynamics Laboratory, National Center for Atmospheric Research, Boulder, Colorado 80307, USA

${ }^{3}$ Institute for Arctic and Alpine Research, University of Colorado, Boulder, CO 80309, USA

${ }^{4}$ Department of Entomology, Cornell University, New York State Agricultural Experiment Station, Geneva, New York 14456, USA

*Corresponding Author

email: stuart.grandy@unh.edu

Keywords: microbes, fauna, earth systems models, food web interactions, soil carbon, biogeochemistry 


\section{Abstract}

2 The explicit representation of microbial communities in soil biogeochemical models is

3 improving their projections, promoting new interdisciplinary research, and stimulating novel

4 theoretical developments. However, microbes are the foundation of complicated soil food webs,

5 with highly intricate and non-linear interactions among trophic groups regulating soil

6 biogeochemical cycles. This food web includes fauna, which influence litter decomposition and

7 the structure and activity of the microbial community. Given the early success of microbial-

8 explicit models, should we also consider explicitly representing faunal activity and physiology in

9 soil biogeochemistry models? Here we explore this question, arguing that the direct effects of

10 fauna on litter decomposition are stronger than on soil organic matter dynamics, and that fauna

11 can have strong indirect effects on soil biogeochemical cycles by influencing microbial

12 population dynamics, but the direction and magnitude of these effects remains too unpredictable

13 for models used to predict global biogeochemical patterns. Given glaring gaps in our

14 understanding of fauna-microbe interactions and how these might play out along climatic and

15 land use gradients, we believe it remains early to explicitly represent fauna in these global-scale

16 models. However, their incorporation into models used for conceptual exploration of food-web

17 interactions or into ecosystem-scale models using site-specific data could provide rich theoretical

18 breakthroughs and provide a starting point for improving model projections across scales. 
25 Soil organic matter (SOM) formation concepts emphasize that plant inputs do not become stable 26 SOM until they first pass through microbial biomass (e.g. Grandy and Neff, 2008; Schmidt et al.

27 2011; Cotrufo et al. 2013). SOM pools derived directly from partially decomposed plant litter 28 (e.g. light fraction or particulate organic matter) typically make up only 5-15\% of total SOM 29 (Gregorich et al. 2006; Grandy and Robertson, 2007); the rest is derived from highly processed, 30 unrecognizable plant-derived inputs and dead microbial biomass (i.e. necromass). Reflecting this 31 new understanding, microbial physiological characteristics including carbon use efficiency

32 (CUE) and microbial growth rate (MGR), both potential drivers of necromass production over 33 time, are emphasized in recent conceptual models (Cotrufo et al. 2013), and have now been 34 experimentally shown in the field (Bradford et al. 2013; Kallenbach et al. 2015) and lab 35 (Kallenbach et al. in review) as drivers of SOM formation.

36 New soil biogeochemistry models are capturing the importance of microbes by explicitly 37 representing microbial communities and their direct contributions to SOM formation (Sulman et 38 al. 2014; Wieder et al. 2014; 2015). These models minimize the direct flow of plant inputs to 39 SOM (Fig. 1). Instead, plant inputs shape the size and activity of the microbial biomass, which is 40 the proximal input to SOM. For example, in the MIcrobial MIneral Carbon Stabilization model 41 (MIMICS), the chemistry of litter inputs influences the kinetics, size, CUE and MGR of the 42 microbial decomposer community (Wieder et al. 2104; 2015), and ultimately how much 43 microbial derived $\mathrm{C}$ is transferred to SOM pools. These new microbial-explicit models appear to 44 more accurately simulate global SOM stocks and their response to perturbations, and, by more 45 accurately representing SOM formation, provide a basis for the linked development of prediction 46 and theory. 
Thus, the representation in models of the microorganisms responsible for SOM

48 transformations is showing promise; yet, the decomposer food web is complex and includes soil

49 fauna, which represent an array of functions that can directly and indirectly influence soil

50 biogeochemical processes. These functions include shredding and redistributing litter, altering

51 soil physical properties including aggregation and pore space structure, microbivory, and

52 accelerating nutrient cycling in soil and litter (Verhoef and Brussaard 1990; Brussaard et al.

53 2007; Coleman 2008). Given the promise of microbial-explicit models, and the range of

54 potential effects of fauna on soil processes and SOM, here we consider the advantages and

55 drawbacks of adding fauna to already complex soil biogeochemistry models (Fig. 1).

57 II. Fauna - A potential driver of microbial necromass production and SOM dynamics

58 Soil fauna have multiple effects on litter decomposition, which is the first step in the formation

59 of SOM (Table 1). For example, the litter comminutors, which reduce litter particle size, can

60 increase the surface area of litter while translocating and inoculating plant material with

61 microbial decomposers (Chamberlain et al. 2006, Soong et al. 2016). Gut passage of plant litter

62 by saprotrophic fauna can also modify litter chemistry and has been shown to enhance microbial

63 activity during early stages of decay, likely due to the enrichment of litter with microbes and

64 creation of decomposition "hotspots" (Hanlon and Anderson 1980; Wickings and Grandy 2011).

65 Meanwhile, bioturbators can alter the distribution of organic matter in soil aggregates and alter

66 the dynamics of decomposition (Tonneijck and Jongmans 2008; Yavitt et al. 2015). Previous

67 studies have also shown that litter decomposition and $\mathrm{N}$ mineralization are sensitive to changes

68 in the overall structure, diversity, density, and activity of faunal communities (Hattenschwiler et

69 al. 2005; David 2014; Wickings et al. 2012; Soong et al. 2016). 
However, while litter decomposition is a critical first step in SOM formation, the two

71 processes are distinct with unique controls. Both are broadly controlled by climate and

72 decomposer community activity, but the biochemical recalcitrance of plant litter (i.e., lignin and

$73 \mathrm{~N}$ concentrations) is a critical factor in litter decomposition but not in SOM dynamics (Rinkes et

74 al. 2013; Kleber et al. 2015). Similarly, although shredding of plant litter by soil meso- and

75 macro-invertebrates is an important control on decomposition rate, its direct downstream effects

76 on SOM dynamics may be relatively diffuse.

In contrast to the overriding effect of recalcitrance on plant litter decomposition, the

78 formation of SOM and its persistence in soils largely depends upon the association of microbial-

79 derived compounds with aggregates and mineral surfaces, which protect SOM from further

80 microbial attack (Grandy and Neff, 2008; Dungait et al. 2012; Heckman et al. 2013). By

81 transforming and redistributing plant litter in soil and by promoting soil aggregation (Bossuyt et

82 al. 2005; Chamberlain et al. 2006; Frouz et al. 2009), litter comminutors and bioturbators may

83 have important effects on the factors that control SOM persistence. However, recent evidence

84 suggests that these fauna-driven processes may have less direct impact on soil microbial

85 communities than previously assumed (Coulis et al. 2013; David 2014). Alternatively,

86 microbivores may have the most direct effects on SOM because of their impact on microbial

87 community activity, growth, and turnover. Microbivory, via direct grazing on microbial biomass

88 or consumption of microbially-colonized substrates, is a key feeding strategy exhibited across a

89 wide range of taxonomic groups and size classes of soil organisms including protozoans,

90 nematodes, annelids and arthropods. By feeding on microbial biomass, fauna exploit the soil

91 microbe's ability to degrade recalcitrant organic matter, and thus bypass the typical low

92 nutritional quality of plant residue. Previous studies have found that microbivory can modify the 
93 structure, diversity, and activity of soil microbial communities. For instance, in a recent meta-

94 analysis, Trap et al. (2016) illustrate that bacterivory by protozoa and nematodes generally

95 reduces soil microbial biomass, but tends to accelerate microbial activity, thus increasing

96 microbial metabolic quotients. In contrast, Crowther et al. (2012) found that microbial grazing,

97 specifically fungivory, led to enhanced microbial biomass. Other studies have also observed that

98 microbial grazing by soil meso- and macrofauna including oribatid mites and isopods can modify

99 microbial activity (Wickings and Grandy 2011; A'Bear et al. 2014). While the magnitude and

100 direction of effects are not consistent, microbivory by a variety of different organisms can alter

101 microbial activity and biomass, which are the proximal controls over SOM dynamics.

102

103 III. How and when - a primer to represent food webs in models

104 As a starting point to incorporating fauna into predictive models, explicit representation of food

105 webs must modify the rate of biogeochemical turnover, or the fate of carbon (C) and nitrogen

106 (N) in soils (Schimel and Schaffer 2012) to justify their complexity. This is likely to occur when

107 biotic interactions modify ecosystem responses to environmental perturbations in unexpected

108 directions (Bradford and Fierer 2012). Fauna-microbe interactions exhibit this potential for

109 unexpected, non-linear response to environmental change. For example, the response of fauna to

110 a changing climate might alter microbial communities in opposite directions to the direct effects

111 of climate on microbial communities. We know that abiotic constraints from energy limitation

112 and substrate availability may broadly limit microbial activity and biogeochemical fluxes across

113 soil environments (Mikola and Setälä, 1998). Accordingly, current biogeochemical models

114 project changes in microbial activity with relaxation of these abiotic constraints, resulting in

115 accelerated soil $\mathrm{C}$ turnover with environmental warming. If, however, changes in temperature, 
116 moisture, or nutrient availability relax these bottom-up constraints on microbial decomposers,

117 one outcome could be that biotic, or top-down controls from food webs dampen the magnitude of

118 ecosystem response, providing a stabilizing effect on ecosystem biogeochemical dynamics

119 (Crowther et al. 2015). These dynamics may not be projected from simpler model structures that 120 ignore food webs.

121 The most straightforward way to begin representing top-down effects in biogeochemical 122 models would be to implicitly represent faunal effects on microbial communities and their

123 activity by modifying static parameters with functions that consider how abiotic factors affect

124 biotic processes and rates of biogeochemical transformations. For example, if warming releases 125 bottom-up limitations on microbial communities, but grazers dampen the observed 126 biogeochemical effects, we could assume a lower temperature sensitivity of soil organic matter 127 turnover (e.g., $\mathrm{Q}_{10}$ value) than would be expected from laboratory incubations or cross-site 128 observations. Current microbial-explicit models, including MIMICS, represent microbial 129 biomass pools with defined turnover and biomass-dependent substrate uptake rates. Fauna could 130 be represented in such models by increasing biomass turnover rates under conditions where 131 microbivores are expected to be especially active, including those with ideal combinations of 132 temperature, moisture and substrate quality. Increasing turnover rates would subsequently 133 decrease standing microbial biomass and substrate uptake rates and potentially alleviate 134 stoichiometric constraints (e.g. $\mathrm{N}$ limitation) in the model. In another scenario, microarthropod 135 alteration of the chemical quality of plant residues that microbes ultimately transform to mineral136 associated SOM (Wickings and Grandy, 2011; Wickings et al. 2012) could be represented by 137 changing the $\mathrm{C}: \mathrm{N}$ ratio of inputs to soil biogeochemical models (Soong, et al. 2016). Lab and 
138 field faunal exclusion experiments across a wide range of ecosystems would further help to 139 parameterize the effects of fauna on microbial activity.

140 Fauna could also be incorporated more explicitly in models by following a food web 141 approach. We could represent fauna as a pool of $\mathrm{C}$ and $\mathrm{N}$ that feeds upon microbial biomass, 142 similar to how microbes in microbial-explicit models currently feed on litter and SOM pools.

143 Previous studies have observed close associations between microbial biomass and the densities 144 of microbivorous nematodes and protozoans (Ingham et al. 1985; Bardgett et al. 1999; and see 145 Review by Trap et al.(2016)). However, the response of soil microbial communities and 146 processes to microbivory is not always consistent, and can vary with microbivory intensity 147 (Crowther et al. 2012a), microbivore community composition (Ronn et al. 2002) and under 148 different soil conditions (Cheng et al. 2016). Thus, additional field experiments would be 149 necessary to test for generalities in the magnitude and direction of the response of microbial 150 biomass and activity to microbivory, and to quantify the importance of microbivore 151 density/activity relative to other constraints on microbial biomass across space and time.

152 Models serve multiple purposes and can operate at different scales. One essential purpose 153 of models is to develop new theory and concepts, some of which may be used to guide 154 experimental work. Theoretical and conceptual models are often a critical first step to developing 155 the insights into specific biogeochemical pools, processes and drivers in soils necessary to 156 develop predictive models. Indeed, the current development of microbial-explicit soil 157 biogeochemical models is based on a rich foundation of conceptual and theoretical models 158 incorporating microbes into SOM dynamics (e.g. Schimel and Weintraub 2003; Allison et al. 159 2010). These models inspired new research leading to improvements in our understanding of 
160 microbes in SOM dynamics and ultimately the incorporation of microbes into models capable of

161 predicting biogeochemical patterns across large spatial and temporal scales (Wieder et al. 2013).

To date, there have been a number of insightful models examining nutrient and energy

163 flows through communities and food-webs, and these have put forward critical predictions and

164 concepts describing the specific role of fauna in biogeochemical transformations (Hendrix et al.

165 1986; Hunt et al. 1987; Verhoef and Brussaad 1990; De Ruiter et al. 1995; Adl and Gupta 2006;

166 Osler and Sommerkorn 2007; Carrillo et al. 2016). However, to begin representing food web

167 interactions in microbial-explicit models that predict ecosystem- or global-scale processes, we

168 must be able to better predict how belowground fauna-microbe interactions change across

169 ecosystems. Despite an extensive and ever-growing understanding of how soil faunal

170 communities vary among systems (e.g. Global Soil Biodiversity Initiative), we believe that we

171 do not currently have this capacity, as key aspects of fauna-microbe interactions that are likely to

172 influence biogeochemical processes remain poorly characterized. For example, while most soil

173 fauna clearly depend on microbes to meet their nutritional demands, the exact mode by which

174 microbes are exploited (endosymbiosis, consumption of microbially-degraded plant tissue, or

175 direct microbivory) can vary significantly among faunal taxa. This variation is likely to have

176 important consequences for downstream SOM dynamics, yet our understanding of the exact

177 modes by which fauna exploit microbes is far from complete (but see Lussenhop 1981;

178 Bonkowski et al. 2000; Maraun et al. 2003; Smrz and Norton 2004; Berg et al. 2004; Crowther et

179 al. 2011). Further yet, the importance of different modes of microbial exploitation under

180 different climatic conditions and disturbance levels is virtually unknown. This currently limits

181 our ability to predict the direction and magnitude of microbial and thus biogeochemical

182 responses to faunal activity under variable scenarios of climate and land-use (Figure 2). Thus, 
183 there remain many potential mechanisms and corresponding mathematical representations of

184 faunal effects and arguably not enough evidence to prioritize supporting one or two mechanisms

185 above all the others in models.

186 Efforts to include fauna-microbe interactions in soil biogeochemistry models would also

187 benefit from a more thorough understanding of belowground predator-prey population dynamics.

188 Density-dependence, for example, is likely to be a critical feature in faunal regulation of 189 microbial biomass and activity. Previous studies have quantified density-dependent

190 relationships between soil fauna and microbial processes (Aira et al. 2008; Kaneda and Kaneko

191 2008; Crowther and A'Bear 2012; A'Bear et al. 2014) and in their recent review Crowther et al.

192 (2012) contrasted the impacts of high versus low intensity fungivory on soil fungal processes.

193 Yet, compared to our understanding of density dependence in governing aboveground trophic

194 interactions, and the delivery of ecosystem services such as pollination, biological control, and

195 primary productivity, our knowledge of how soil microbial processes respond, both in magnitude

196 and direction, to changes in faunal density across time and space is still incomplete. Thus, many

197 questions remain about the fundamental relationships between microbes and fauna and how they

198 may relate to SOM formation and persistence: Does microbivore population size consistently

199 track that of soil microbial biomass? Which fauna-microbe interaction type (stimulation or

200 suppression) leads to greater accumulation of microbial products in soil? What is the

201 relationship between microbivory rate and substrate use efficiency of saprotrophic microbes?

202 Until such questions are more thoroughly addressed across spatial and temporal scales,

203 incorporating fauna into Earth system models will not improve confidence in model projections.

204 Further, caution should always be used when increasing the structural complexity of models

205 operating at large spatial scales in order to avoid problems with computational constraints and 
206 the potential of developing a model that can replicate existing data but inaccurately represents

207 the real world and thus future scenarios (i.e. 'equifinality'; Beven and Freer 2001; Luo et al.

208 2009). However, incorporating an explicit biomass pool for fauna would allow for theoretical

209 exploration of the effects of microbivory and top-down effects of fauna upon soil organic matter

210 dynamics. Incorporating fauna into theoretical models and into ecosystem soil models will

211 enhance dialogue between modelers, ecologists and soil scientists, and provide a basis for

212 extending these efforts to larger scales (Tang and Zhuang 2008).

213

214 


\section{Figure legends}

217 Figure 1. Three simple conceptual representations of different ways microbes and fauna could be

218 represented in models. Microbial Implicit. Microbial kinetics and growth efficiencies are 219 typically static parameters embedded in the model (e.g. decay constants or transfer efficiencies 220 between SOM pools) or less frequently scale with environmental parameters, but are not 221 explicitly a function of microbial community characteristics. These models emphasize the 222 importance of enzymatically degraded plant litter in SOM formation. Microbial-explicit, bottom223 up. Microbial processes and/or communities are explicitly represented in the model. Growth 224 efficiencies, growth rates, and decomposition kinetics may vary among communities. These 225 models emphasize the importance of microbial necromass contributions to soil organic matter 226 (SOM formation). Microbial-explicit, top-down with fauna. Similar to microbial-explicit, 227 bottom-up models, but microbivory by microarthropods (represented here) and fungal- and 228 bacterial-feeding nematodes provides a constraint on microbial community size and physiology 229 and thus SOM formation. Although fauna can have a range of effects on litter decomposition and 230 SOM formation, here we focus on microbivory because of its potential influence over the size, 231 turnover, and efficiency of the microbial biomass, the proximal input to SOM.

233 Figure 2. Potential fauna effects on microbial activity in response to temperature. Microbial 234 activity increases with temperature up to their temperature maximum (here using $35^{\circ} \mathrm{C}$ only as an 235 example). Fauna may have a narrower temperature range of activity than microbes (here 236 generalized as $10-30^{\circ} \mathrm{C}$ ), and over this range of activity fauna may either decrease or increase 
237 microbial activity (represented by hashed lines and shading, highlighting the potential variation

238 in microbial activity due to fauna).

239

240

\section{Acknowledgements}

242 W.R.W. is supported by funding from the US Department of Agriculture NIFA 2015-67003243 23485, the US Department of Energy TES DE-SC0014374, and the U.S. Geological Survey

244 Ecosystems Mission Area and New Hampshire Agricultural Experiment Station. A.S. Grandy 245 and E. Kyker Snowman are supported by United States Department of Agriculture NIFA

246 Foundational Program, grant \#2014-67019-21716, and by USDA \#2015-35615-22747, and $247 \quad \# 2015-42247-519119$. 


\section{References cited}

A'Bear, A.D., Boddy, L., Kandeler, E., Ruess, L., Jones, T.H., 2014. Effects of isopod population density on woodland decomposer microbial community function. Soil Biology and Biochemistry 77, 112-120.

Adl, M.S., Gupta, V.V.S.R. 2006. Protists in soil ecology and forest nutrient cycling. Canadian Journal of Forest Research. 36: 1805-1817.

Aira, M., Sampedro, L., Monroy, F., Dominguez, J., 2008. Detritivorous earthworms directly modify the structure, thus altering the functioning of a microdecomposer food web. Soil Biology and Biochemistry 40, 2511-2516.

Allison, S. D., M. D. Wallenstein, and M. A. Bradford., 2010. Soil-carbon response to warming dependent on microbial physiology, Nat. Geosci., 3(5), 336-340.

Bardgett, R.D., Cook, R., Yeates, G.W., C.S. Denton., 1999. The influence of nematodes on below-ground processes in grassland ecosystems, Plant Soil 212,22-33.

Berg, M.P., Stoffer, J., Van Den Heuvel, H.H., 2004. Feeding guilds in Collembola based on digestive enzymes. Pedobiologia 48: 589-601.

Beven, K., and J. Freer. 2001. Equifinality, data assimilation, and uncertainty estimation in mechanistic modelling of complex environmental systems using the GLUE methodology." Journal of Hydrology 249: 11-29.

Bonkowski, M., Griffiths, B.S., Ritz, K., 2000. Food preferences of earthworms for soil fungi. Pedobiologia 44, 666-676.

Bossuyt, H.,, Six, J., Hendrix, P.F. 2005. Protection of soil carbon by microaggregates within earthworm casts. Soil Biol Biochem 37:251-258

Bradford, M. A., Fierer, N., 2012. The biogeography of microbial communities and ecosystem processes: implications for soil and ecosystem models. Soil Ecology and Ecosystem Services, 189-200.

Bradford, M.A., Keiser, A.D., Davies, C.A., Mersmann, C.A., Strickland, M.S., 2013. Empirical evidence that soil carbon formation from plant inputs is positively related to microbial growth. Biogeochemistry 113, 271-281.

Carrillo, Y., Ball, B.A., Marirosa, M., 2016. Stoichiometric linkages between plant litter, trophic interactions and nitrogen mineralization across the litter-soil interface. Soil Biology and Biochemistry. 92, 102-110.

Chamberlain, P.M., N.P. McNamara, J. Chaplow, A.W. Stott, and H.I.J. Black. 2006.

Translocation of surface litter carbon into soil by Collembola. Soil Biology \& Biochemistry, 38, 2655-2664. 
Cheng, Y., Jiang, Y., Wu, Y., Valentine, T.A., Li, H., 2016. Soil nitrogen status modifies rice root response to nematode-bacteria interactions in the rhizosphere. PLoS One 11: e0148021.

Coleman, D.C., 2008. From peds to paradoxes: Linkages between soil biota and their influences on ecological processes. Soil Biology and Biochemistry 40, 271-289.

Cotrufo, M.F., Wallenstein, M.D., Boot, C.M., Denef, K., Paul, E., 2013. The Microbial Efficiency-Matrix Stabilization (MEMS) framework integrates plant litter decomposition with soil organic matter stabilization: do labile plant inputs form stable soil organic matter? Global Change Biology 19, 988-95.

Coulis, M., Hättenschwiler, Fromin, N., David, J.F. 2013 Macroarthropod-microorganism interactions during the decomposition of Mediterranean shrub litter at different moisture levels. Soil Biology \& Biochemistry 64: 114-121.

Crowther, T. W., A'Bear, A.D., 2012. Impacts of grazing soil fauna on decomposer fungi are species-specific and density-dependent. Fungal Ecology 5, 277-281.

Crowther, T.W., Boddy, L., Jones, T.H., 2011. Species-specific effects of soil fauna on fungal foraging and decomposition. Oecologia 167, 535-545.

Crowther, T.W., Boddy, L., Jones, T.H., 2012. Functional and ecological consequences of saprotrophic fungus-grazer interactions. ISME Journal 6, 1992-2001.

Crowther, T.W., Sokol, N.W., Oldfield, E.E., Maynard, D.S., Thomas, S.M., Bradford, M.A., 2015. Environmental stress response limits microbial necromass contributions to soil organic carbon. Soil Biology and Biochemistry 85, 153-161.

David, J.F. 2014. The role of litter-feeding macroarthropods in decomposition processes: a reappraisal of common views. Soil Biology and Biochemistry, 76:109-118.

De Ruiter, P., Neutel, A.M., Moore, J.C., 1995. Energetics, patterns of interaction strengths, and stability in real ecosystems. Science, 269, 1257-1260.

Dungait, J. A. J., D. W. Hopkins, A. S. Gregory, and A. P. Whitmore. 2012. Soil organic matter turnover is governed by accessibility not recalcitrance, Global Change Biol, 18, 1781-1796.

Frouz J., Pizl, V., Cienciala, E., Kalcik, J. 2009. Carbon storage in post-mining forest soil, the role of tree biomass and soil bioturbation. Biogeochemistry. 94: 111-121.

Grandy, A.S., Neff, J.C., 2008. Molecular C dynamics downstream: the biochemical decomposition sequence and its impact on soil organic matter structure and function. Science of the Total Environment 404, 297-307.

Grandy, A.S., Robertson, G.P., 2007. Land-use intensity effects on soil organic carbon accumulation rates and mechanisms. Ecosystems 10, 58-73.

Gregorich, E.G., Beare, M.H., Mckim, U.F., Skjemstad, J.O., 2006. Chemical and biological 
characteristics of physically uncomplexed organic matter. Soil Science Society of America 70, 975-985.

Hanlon, R.D.G., and J.M. Anderson. 1980. Influence of macroarthropod feeding activities on microflora in decomposing oak leaves. Soil Biology \& Biochemistry, 12:255-261.

Hattenschwiler, S., Tiunov, A.V., Scheu, S., 2005. Biodiversity and litter decomposition in terrestrial ecosystems. Annual Review of Ecology Evolution and Systematics 36, 191-218.

Heckman, K.A., A.S. Grandy, G. Xiaodong, M. Keiluweit, K. Wickings*, K. Carpenter, J. Chorover, C. Rasmussen. 2013. Sorptive fractionation of organic matter and formation of organohydroxy-aluminum complexes during litter biodegradation in the presence of gibbsite. Geochimica et Cosmochimica Acta 121, 667-683.

Hendrix, P.F., Parmelee, R.W., Crossley, Jr. D.A., Coleman, D.C., Odum, E.P., Groffman, P.M., 1986. Detritus food webs in conventional and no-tillage agroecosystems. Bioscience 36, 374380.

Hunt, H.W., Coleman, D.C., Ingham, E.R., Ingham, R.E., Elliot, E.T., Moore, J.C., Rose, S.L., Reid, C.P.P., Morley, C.R., 1987. The detrital food web in a shortgrass prairie. Biology and Fertility of Soils. 3: 57-68.

Ingham, R.E., J.A. Trofymow, E.R. Ingham, D.C. Coleman., 1985. Interactions of bacteria, fungi and their nematode grazers: effects on nutrient cycling and plant growth, Ecol. Monogr 55,119140 .

Kallenbach, C.M., Grandy, A.S., Frey, S.D., Diefendorf, A. F., 2015. Microbial physiology and necromass regulate agricultural soil carbon accumulation. Soil Biology \& Biochemistry 9, 279290.

Kallenbach, C.M., Grandy, A.S., Frey, S.D., In Review. Direct evidence for microbial-derived soil organic matter formation and its ecophysiological controls. Nature Communications, in review

Kaneda, S., Kaneko, N., 2008. Collembolans feeding on soil affect carbon and nitrogen mineralization by their influence on microbial and nematode activities. Biology and Fertility of Soils 44, 435-442.

Kleber, M., Eusterhues, K., Keiluweit, M., Mikutta, C., Mikutta, R. and P. S. Nico. 2015. Mineral-Organic Associations: Formation, Properties, and Relevance in Soil Environments. Advances in Agronomy 130, 1-140.

Lijbert, B., Pulleman M.M., Ouedraogo, E., et al., 2006. Soil fauna and soil function in the fabric of the food web. Pedobiologia 50, 447-462.

Luo, Y., E. Wang, X. Wu, L. Zhang. 2009. Parameter identifiability, constraint, and equifinality in data assimilation with ecosystem models. Ecological Applications 19.3 (2009): 571-574. 
Lussenhop, J., 1981. Microbial and micro arthropod detrital processing in a prairie soil. Ecology 62, 964-972.

Maraun, M., Martens, H., Migge, S., Theenhaus, A., Scheu, S., 2003. Adding to 'the enigma of soil animal diversity': Fungal feeders and saprophagous soil invertebrates prefer similar food substrates. European Journal of Soil Biology 39, 85-95.

Mikola, J., Setälä, H., 1998. No evidence of trophic cascades in an experimental microbial-based soil food web. Ecology 79, 153-164.Rinkes, Z.L., R.L. Sinsabaugh, D.L. Moorhead, A.S. Grandy, and M.N. Weintraub. 2013. Field and lab conditions alter microbial enzyme and biomass driving decomposition of the same leaf litter. Frontiers in Terrestrial Microbiology 4,114.

Osler, G.H.R., and M. 2007. Toward a complete soil C and N cycle: Incorporating the soil fauna. Ecology, 88:1611-1621

Rinkes, Z.L., R.L. Sinsabaugh, D.L. Moorhead, A.S. Grandy, and M.N. Weintraub. 2013. Field and lab conditions alter microbial enzyme and biomass driving decomposition of the same leaf litter. Frontiers in Terrestrial Microbiology, 4:1-14.

Rønn, A.E. McCaig, B.S. Griffiths, J.I. Prosser., 2002. Impact of protozoan grazing on bacterial community structure in soil microcosms, Appl. Environ. Microbiol 68, 6094-6105.

Schimel, J. P., and M. N. Weintraub,. 2003. The implications of exoenzyme activity on microbial carbon and nitrogen limitation in soil: A theoretical model, Soil Biol. Biochem 35, 549-563.

Schimel, J., Schaeffer, S.M., 2012. Microbial control over carbon cycling in soil. Frontiers in Microbiology 3, 348.

Schmidt, M.W.I., Torn, M.S., Abiven, S., Dittmar, T., Guggenberger, G., Janssens, I.A., Kleber, Kögel-Knabner, M., I., Lehmann, J., Manning, D.A.C., Nannipieri, P., Rasse, D.P., Weiner, S., Trumbore, S.E., 2011. Persistence of soil organic matter as an ecosystem property. Nature 478, 49-56.

Smrz, J., Norton, R.A., 2004. Food selection and internal processing in Archcesozetes longisetosus (Acari: Oribatida). Pedobiologia 48, 111-120.

Soong, J.L., Vandegehuchte, M.L., Horton, A.J., Nielsen, U.N., Denef, K., Shaw, E.A., de Tomasel, C.M., Parton, W., Wall, D.H., Cotrufo, M.F., 2016. Soil microarthropods support ecosystem productivity and soil $\mathrm{C}$ accrual: Evidence from a litter decomposition study in the tallgrass prairie. Soil Biology and Biochemistry 92, 230-238.

Sulman, B.N., Phillips, R.P., Oishi, A.C., Shevliakova, E., Pacala, S.W., 2014. Microbe-driven turnover offsets mineral-mediated storage of soil carbon under elevated CO2. Nature Climate Change 4, 1099-1102.

Tang, J., and Q. Zhuang., 2008. Equifinality in parameterization of process-based biogeochemistry models: A significant uncertainty source to the estimation of regional carbon 
dynamics, J. Geophys. Res 113.

Tonneijck, F.H., and A.G. Jongmans. 2008. The influence of bioturbation on the vertical distribution of soil organic matter in volcanic ash soils: a case study in northern Ecuador. European Journal of Soil Science. 59 1063-1075.

Trap, J., Bonkowski, M., Plassard, C., Villenave, C., Blanchart, E. 2016. Ecological importance of soil bacterivores for ecosystem functions. Plant Soil 398: 1-24.

Verhoef, H.A., Brussaard, L., 1990. Decomposition and nitrogen mineralization and agroecosystems- The contribution of soil animals. Biogeochemistry 11, 175-211.

Wickings, K., Grandy, A.S., 2011. The oribatid mite Scheloribates moestus (Acari: Oribatida) alters litter chemistry and nutrient cycling during decomposition. Soil Biology \& Biochemistry 43, 351-358.

Wickings, K., Grandy, A.S., Reed, S., Cleveland, C., 2012. The origin of litter chemical complexity during decomposition. Ecology Letters 15, 1180-1188.

Wieder, W. R., A. S. Grandy, C. M. Kallenbach, P. G. Taylor, and G. B. Bonan., 2015. Representing life in the Earth system with soil microbial functional traits in the MIMICS model. Geoscientific Model Development 8, 1789-1808.

Wieder, W. R., G. B. Bonan, and S. D. Allison., 2013. Global soil carbon projections are improved by modeling microbial processes, Nat. Clim. Change 3, 909-912.

Wieder, W.R., Grandy, A.S., Kallenbach, C.M., Bonan, G.B., 2014. Integrating microbial physiology and physiochemical principles in soils with the Microbial Mineral Carbon Stabilization (MIMICS) model. Biogeosciences 11, 3899-3917.

Yavitt, J. B., Fahey, T. J., Sherman, R. E., Groffman, P. M. 2015. Lumbricid earthworm effects on incorporation of root and leaf litter into aggregates in a forest soil, New York State. Biogeochemistry. 125:261-273. 


\begin{tabular}{|l|l|l|}
\hline Faunal Functional Group & Effects on Litter Decomposition & Potential Effects on SOM formation/recycling \\
\hline Comminution & $\begin{array}{l}\text { Increased surface area } \\
\text { Translocation, redistribution } \\
\text { Inoculation } \\
\text { Increasing moisture }\end{array}$ & Altered microbial substrate availability and spatial \\
\hline Microbivory & $\begin{array}{l}\text { Suppression of decomposition through overgrazing } \\
\text { Stimulating growth, turnover, activity } \\
\text { Stoichiometry, chemical changes } \\
\text { Microbial community structure (density-dependent effect?) }\end{array}$ & Influence on microbial products and enzymes \\
\hline Bioturbation & $\begin{array}{l}\text { Soil } \mathrm{O}_{2}, \text { moisture mixing } \\
\text { Translocation/redistribution } \\
\text { Resource heterogeneity } \\
\text { Chemical controls on microbial community }\end{array}$ & $\begin{array}{l}\text { Aggregation } \\
\text { Soil Physical Properties } \\
\text { Resource Heterogeneity } \\
\text { pH, other chemical properties }\end{array}$ \\
\hline
\end{tabular}




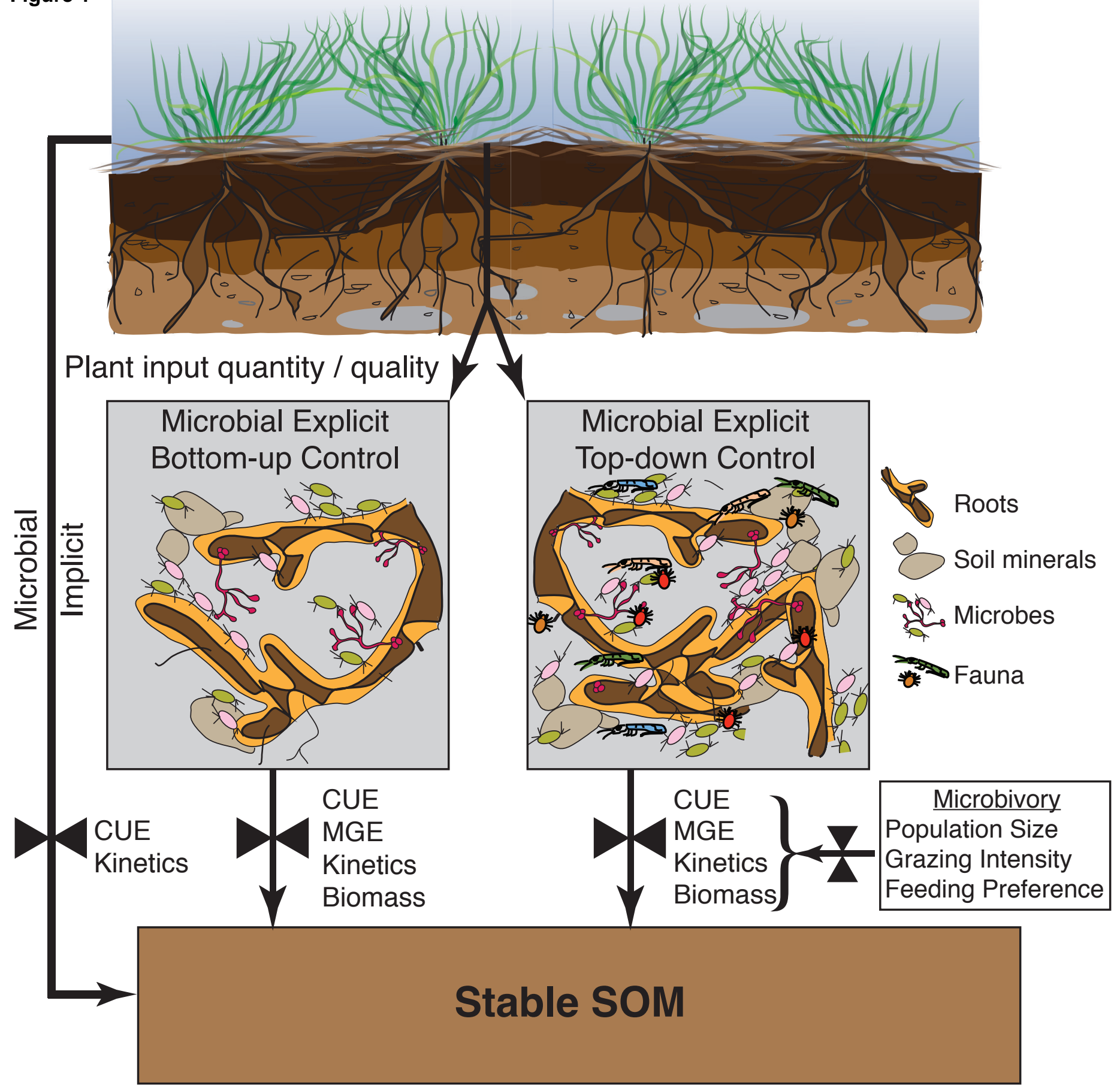


